\title{
Proposing a Novel Mathematical Model and Meta-Heuristic Algorithm for University Course Timetabling with an Educational Quality Approach; a Case Study
}

\author{
Professor Dr. Sorush Niknamian \\ Board Member of Weston A Price Foundation, Washington DC, USA \\ Email: so.niknamian@gmail.com
}

\begin{abstract}
One of the imperative tasks of universities, which is usually challenging, are university course timetabling problems. These problems are confronted with, every year and term and directly influence the educational performance. In the university course timetabling problem, the university sources including modules, lecturers, classes and other teaching bases are allotted to a series of time-periods. If they are assigned appropriately, educational quality can be enhanced. With due attention to the importance of this issue, a new mathematical model is proposed in this study, for university course timetabling. indexes of educational quality, such as, the merit of lecturers in teaching, period for student counseling and a suitable phase for the presentation of tutorials, during the day, are taken into account in this model. In considering that, university course timetabling problem is in vast NP-Hard dimensions, a meta-heuristic algorithm is employed, based on a non-dominated sorting genetic algorithm. Given that, the algorithm proposes several ranked solutions, the final solution is selected by defining some indexes to measure the quality of solutions, utilizing multi-criteria methods. Finally, the course timetabling for graduate studies of the Department of Industries at the Islamic Azad University (Najaf Abad Branch), was determined by means of this algorithm.
\end{abstract}

Keywords: Non-dominated Sorting Genetic Algorithm II (NSGA II), Educational Quality, VIKOR.

\section{Introduction}

The scheduling aspect is one of the activities, which is used in different tasks and has been recognized as a challenging action, which many researchers have explored in recent years. Timetabling of university courses, classes, lecturers and all educational possibilities is one of the perplexing issues in university activities, which they are permanently and periodically faced with (Mendez-Diaz et al., 2016). A group of programming elements are structured in the university course timetabling problems, taking the various restrictions present, into consideration (Domenech \& Lusa, 2015).

Timetabling problem for university courses will normally be engulfed with many assets, followed by restrictions. Thus, planning in view of these problems encounters many complexities. University course timetabling includes a series such as, lecturers, classes, time-periods, laboratory prospects and..... Each source has its own specific limitations which are consigned to lessons in the form of a timetable and hence, the university course timetabling is created (Goh et al., 2017).

Several studies have been carried out on university course timetabling problems. In considering previous studies, Carter and Laporte (1998) divided this problem into five categories that are as follows: 
$\checkmark$ Course timetable: Comprises of the timetabling of existing courses in the curriculum of the university or colleges, according to the classrooms and lecturers in access.

$\checkmark$ Lecturers-course timetabling: In this table, an intervention of the lecturers' program is surveyed in concern with the allocation of classrooms and courses.

$\checkmark$ Student timetabling: Capacity of courses for each time -period is determined, so that the students can select the courses.

$\checkmark$ Assignment of lecturers: The lecturers are assigned to courses based on the relative timetable.

$\checkmark$ Allocation of classrooms: The classrooms are allotted to the measures taken in the program.

In respect to the abovementioned, for the five classes under consideration, one or more plans are usually determined, in studies that are executed, on university course timetabling (Domenech \& Lusa, 2015). Generally speaking, when the number of courses, classes, and lecturers is increased in university course timetabling problems, it is converted into a NP-Hard problem and solving this, requires heuristic and metaheuristic algorithms (such as simulated annealing, genetic algorithms or tabu search) (Carter \& Laporte, 1998; Domenech \& Lusa, 2015).

Given the intricacy of university course timetabling, researchers have presented various models and methods for solving it and they have also explored different constraints in these models; but a very important point in university course timetabling is being attentive towards the indexes and evidences of the quality of education. Hence, the current study, proposes a new mathematical model for university course timetabling by means of a quality-oriented approach. Some constraints, which have been considered, to enhance educational quality, are rendered below:

$\checkmark$ Instruction quality of Lecturers: given that the assignment of various lecturers differs and the quality of presentation of each tutorial given by them is dissimilar, the aim in the proposed model is to maximize the task of lecturers, in rendering a higher quality, to each tutorial.

$\checkmark$ The student counseling session: with due attention to the fact that, students require counseling to solve their problems during their presence at the university, a limit has been considered in this regard in the proposed model, so that, in the maximum, one lecturer is present during the faculty hours.

$\checkmark$ Appropriate time rendered for the presentation of tutorial: In considering the timing of the courses and a compact scheduling, shall be time saving for the students and lecturers, including a reduction in the commuting aspects, is one of the limitations denoted in this relative.

$\checkmark$ Preference of designating faculty members rather than visiting lecturers: given that, faculty members of every university incur lower costs for the university, rather than the visiting or (flying) lecturers and students have more access to them, faculty members are preferred, to visiting lecturers in the model.

In taking into consideration the abovementioned issues, in relevance to the university course timetabling problem, a mathematical model is proposed in this study for university course timetabling, so as to enhance educational quality. The model is then used to schedule courses in the Department of Industries at the Islamic Azad University (Najaf Abad Branch). Given that the size of the model is a NP-Hard one, a university course planning, multi-objective, non-dominated genetic algorithm was presented and it was 
utilized for planning graduate courses at the Department of Industries. Finally, with due attention to the fact that, the algorithm, has numerous ranked responses, a multi-criteria decision-making aspect, was resorted to.

\section{Research background}

In relative to timetabling problems for university courses and methods to resolve it, several studies have been performed. In this section, some of these studies are mentioned and classified.

Phillips et al. (2014) proposed an integer programming model for the allocation of classes to university courses. The new model is a generalized model of the previous models and is suitable for examples of different sizes. The proposed model was verified at the University of Auckland and the results were surveyed.

Domenech and Lusa (2015) offered a mixed -integer linear programming model, to balance the teaching level of lecturers (as the first index) and maximize the preferences of the lecturers, on the basis of their classification (as the second index). The proposed model rendered in this paper was employed to allot lecturers to courses in the Department of Management and Industrial Engineering at the University of Barcelona in Catalonia. The results were discussed based on the two determined indexes. The results illustrated that, the proposed model is suitable to be utilized for a number of varied lecturers and tutorials.

Vermuyten et al. (2016) presented a two-stage integer programming model to create a timetable for academic courses. Their purpose was to minimize the flow of students on the university campus. In the first step, it reduced the rate of curriculum violations and educational priorities to the minimum, in relevance to the lecturers, as it assigned them to time-periods and classes. In the second stage, classes were yet again, allocated to the courses in the previous stage and the commuting of students was minimized.

In another research, Mendez-Diaz et al. (2016) surveyed the university course timetabling problem, by taking the details into account. For this purpose, they rendered an integer linear programming model and an exploratory algorithm. The proposed model and algorithm were executed in a private university in Buenos Aires, Argentina; and its results demonstrated the ability to execute the model and provide logical solutions of high quality.

Bellio et al. (2016) also investigated university course timetabling and considered two classes of innovations. Hence, they first proposed a simulated annealing method for solving the problem and then presented an extensive statistical method to create parameters for the algorithm. The results of this model allow determining parameters of the algorithm, by means of the data and as a result, appropriate and high quality solutions are created.

Goh et al. (2017) combined repetitive local search algorithms for solving university course timetabling problems in two phases. In the first phase, they used the Tabu Search Algorithm to produce practical solutions. In the second stage, they presented an improved simulated annealing algorithm and proposed a simulated annealing with reheating. The results of this method were used in timetabling three samples of data based on circumstances and showed better results in most conditions.

Borchani et al. (2017) suggested the variable neighborhood descent search based algorithms, to solve university course timetabling problems. The purpose was to decrease the number of time-periods in the university timetable as well as the number of single lessons in the timetable of each group of students. In 
this algorithm, eleven special neighboring structures were considered. Six structures were taken into account to modify time-periods and five structures were used to regulate the timetable of the selected lesson. This algorithm was implemented at a university in Tunisia and it was tested for practicability. The obtained results revealed that the timetable has a better performance when more than $50 \%$ of the time-periods are omitted.

In addition to above studies, a large number of researchers have used various meta-heuristic algorithms to solve the university course timetabling problem. A summary of it is shown in Table 1. 


\section{University course timetabling}

The university course timetabling problem is recognized as one of the most difficult university problems with which educational institutions are faced. Given that they are confronted with it permanently and periodically, is of great importance. In this problem, programming is performed in order to assign a group of lessons, trainings, and scientific activities to a number of lecturers, classrooms, and time-periods in the programming horizon. Soft and hard constraints or restrictions must be considered in this programming (Borchani et al., 2017).

University course timetabling problem includes a series of soft and hard constraints. Every acceptable timetable should respond to all hard constraints but it does not need to respond to all soft constraints. Rather, it should maintain the soft constraints at a satisfactory level. In other words, soft constraints are usually in the form of model objectives and hard constraints are within the mold of restrictions (Zhang et al., 2010). One of the important problems among the surveys on the university course timetabling problem is the limitations of this problem. Some of these are mentioned in Table 2.

University course timetabling problem do not have a fixed and definite solution and many researchers have proposed different models for it and solved it through various methods (MirHassani, 2006).

\section{Problem description}

Many researchers have considered university course timetabling problems and numerous studies have been conducted by taking the various constraints into account. As outlined in the previous section, the limitations that have already been considered, in university course timetabling problem are based on the schedule of academic courses on the grounds of common restraints at universities and educational quality constraints have been less widely used. Moreover, with due attention to the importance of the educational quality presented by universities, besides those of previous researchers, the present study, considers the restrictions related to the quality of education.

Therefore, a mathematical model is proposed in the current study for university course timetabling. Given that the university course timetabling problem is converted into a NP-Hard problem at a large scale, a metaheuristic algorithm is presented, on the basis of a multi-objective sorting genetic algorithm. As several answers are rendered, some indexes are determined to evaluate the quality of the solutions and the final explanation is selected by a multiple-criteria decision-making technique. Finally, the proposed algorithm was used for course timetabling in the Department of Industries at the Islamic Azad University, (Najaf Abad Branch) and the results are analyzed.

In considering the soft and hard constraints utilized in the previous studies, as well as those in relevance to the quality of education, the constraints considered in this study are as follows:

\section{Soft constraints:}

$\checkmark \quad$ The preference of engaging faculty members rather than having visiting lecturers: given that faculty members of each university impose lower cost for tutorials, to the university than the flying lecturers, or those invited. Furthermore, the former are more in access for the students; so, faculty members are preferred in the model, rather than inviting lecturers. 
$\checkmark$ Minimizing the presentation of tutorials at the closing time-period of each day: with due attention to the fact that, the students are more exhausted at the final time-period of each day, the lessons presented are in the minimal.

$\checkmark$ The conduction of synchronous and optional courses: Due to the fact that, there is no feasibility for students to take pre-requisite and (optional) other courses, thus, a simultaneous presentation of these courses helps compression of programming.

$\checkmark$ The excellence of lecturers: given that various lecturers can render courses, they should be allotted to lecturers who excel and are of higher quality (for tutorials) to the utmost.

$\checkmark$ Maximizing the deployment of lecturers: in order to decrease the commuting aspects of the lecturers, maximum use of lecturers must be made, on days of their attendance at the university.

$\checkmark \quad$ Maximizing the utilization of a classroom by a lecturer: to prevent a large number of lecturers from shifting amongst classrooms, the use of a classroom for a lecturer is maximized.

\section{Hard constraints:}

$\checkmark$ Curriculum of lecturers based on the hours of their university attendance: according to this constraint, tutorial programming is performed for the lecturers, only when they attend the university.

$\checkmark$ Abstaining from intervening in the programs of the lecturers: on the basis of this limitation, each lecturer cannot tutor more than one lesson during each time-period.

$\checkmark \quad$ The maximum amount of tutorials for each lecturer per day: on the founding of this constraint, each lecturer cannot teach for more than a specific time per day.

$\checkmark$ Creating provisions for all the groups of a tutorial: all the groups, which have been predicted for each lesson in the programming, should be taken into consideration in the timetable.

$\checkmark$ Refraining from intruding in respect to the location of classrooms for holding classes: in accordance with this limitation, a classroom does not have the possibility of holding more than one tutorial at every time-period.

$\checkmark$ Classroom Capacity: the lessons are assigned to classes, which have a higher capacity rather than those having the capability in relevance to the tutorial.

$\checkmark$ Taking the capacity of lecturers for teaching under consideration: in this relative, lecturers can only teach for specific periods throughout the week.

$\checkmark$ Obligatory attendance of a faculty member for impromptu counseling: in order to improve the quality of education and to respond to the questions of the students, a lecturer must be in attendance at the University for counseling.

\section{Mathematical model}

The proposed mathematical model is used for university course timetabling. Lecturers, classes and tutorials are assigned to a series of time-periods in each day. The above-mentioned constraints are also considered in the programming. In the proposed model, $i=\{1,2, \ldots, I\}$ illustrates the whole set of lessons, $j=$ $\{1,2, \ldots, J\}$ shows the days, $r=\{1,2, \ldots, P\}$ indicates the divisions or dissections of each day (midday $)^{1}, \mathrm{k}=$ $\{1,2, \ldots, \mathrm{K}\}$ shows the whole set of time-periods at the (or till midday) division $r$ from day $j, \mathrm{~m}=\{1,2, \ldots, \mathrm{M}\}$

\footnotetext{
${ }^{1}$ Dissection or division of the day for university tutorials are accounted for, according to two intervals of time or sessions i.e. from morning to noon (or midday) and from afternoon to evening or dusk.
} 
demonstrates the entire classrooms, $p=\{1,2, \ldots, P\}$ shows all the lecturers, and $v=\{1,2, \ldots, V\}$ illustrates the number of units of courses. Model parameters on the basis of the existing constraints and variables in the model are presented in Table 3.

The variable in this model is $\mathrm{C}_{\mathrm{ijkvmmp}}$ that indicates if the v-unit course $i$ in day $j$, midday $r$, time -period $k$ is assigned to class $m$ and lecturer $p$, it is equal to 1 ; otherwise, it will be equal to zero.

In continuation, a mathematical model of university course timetabling is rendered. This model has 8 objective classes and 14 constraint classes. They will be explained below in segregation.

In the first formula of the proposed model, the objective is to maximize the use of the existing classrooms as per daily division, (midday). In other words, each classroom is used to the maximum each day and at midday, on the purpose of this basis. Efforts are made to minimize the time when each classroom is empty between classes (tutorials). This soft constraint is shown in Formula 1:

$$
\max =\frac{\sum_{i=1}^{I} \sum_{k=1}^{K} \sum_{v=1}^{V} \sum_{p=1}^{P} C_{i j r k v m p}}{\sum_{v=1}^{V} M K_{r v}} \quad \forall j, r, m
$$

In the second objective, the maximum deployment of one lecturer during the day and time-periods of his/her attendance at the university is taken under contemplation. In other words, this formula tries to minimize the futile period for lecturers in a day. This is displayed in Formula 2:

$$
\max =\frac{\sum_{i=1}^{I} \sum_{r=1}^{R} \sum_{k=1}^{K} \sum_{v=1}^{V} \sum_{m=1}^{M} C_{i j r k v m p} * C T_{p i}}{\sum_{r=1}^{R} \sum_{k=1}^{K} \sum_{v=1}^{V} M T_{p j r k v}} \quad \forall j, p
$$

A minimization for an additional capacity of classrooms is considered in Formula 3. Those courses which require much lesser space, than the classroom capacity are not held there.

$$
\min =\frac{C_{m}-\sum_{i=1}^{I} \sum_{v=1}^{V} \sum_{p=1}^{P} C_{i j r k v m p} * S_{i}}{C_{m}} \quad \forall j, r, k, m \text { (3) }
$$

In Formula 4, of the mathematical model, the maximum utilization of a classroom is considered for a lecturer; that is, this formula assists in minimizing the lecturers' movement between classrooms.

$$
\max =\frac{\sum_{i=1}^{I} \sum_{r=1}^{R} \sum_{k=1}^{K} \sum_{v=1}^{V} C_{i j r k v m p} * C T_{p i}}{\sum_{r=1}^{R} \sum_{k=1}^{K} \sum_{v=1}^{V} M T_{p j r k v}} \quad \forall j, m, p
$$

In order to maximize the deployment of faculty members, in respect to having visiting or flying lecturers in the programming, Formula 5 is employed. Given that the lecturers $1-n$ are the faculty members, this correlation helps to assign more faculty members. 


$$
\begin{aligned}
\max =\left(\sum_{i=1}^{I} \sum_{j=1}^{J}\right. & \left.\sum_{r=1}^{R} \sum_{k=1}^{K} \sum_{v=1}^{V} \sum_{m=1}^{M} \sum_{p=1}^{n} C_{i j r k v m p} * C T_{p i}\right) \\
& -\left(\sum_{i=1}^{I} \sum_{j=1}^{J} \sum_{r=1}^{R} \sum_{k=1}^{K} \sum_{v=1}^{V} \sum_{m=1}^{M} \sum_{p=n+1}^{P} C_{i j r k v m p} * C T_{p i}\right)
\end{aligned}
$$

In Formula 6, the excellence of the assigned lecturers in relevance to the courses is maximized; i.e. this correlation shows that, the courses are allotted to lecturers of higher superiority in relative to that course.

$$
\max =\frac{\sum_{i=1}^{I} \sum_{j=1}^{J} \sum_{r=1}^{R} \sum_{k=1}^{K} \sum_{v=1}^{V} \sum_{m=1}^{M} \sum_{p=1}^{P} C_{i j r k v m p} * Q_{p i}}{\sum_{i=1}^{I} \sum_{p=1}^{P} Q_{p i}}
$$

In considering that, the students cannot select all the required courses simultaneously, Formula 7 indicates the maximum presentation of these courses simultaneously.

$$
\max \sum_{v=1}^{V} \sum_{m=1}^{M} \sum_{p=1}^{P} W_{i i^{\prime}} *\left(C_{i j r k v m p}+C_{i^{\prime} j r k v m p}\right) \quad \begin{aligned}
& \forall i, r, j, k \\
& i \neq i^{\prime}
\end{aligned}
$$

In Formula 7, if course $i$ is the pre-requisite for course $i^{\prime}$ and course $i^{\prime}$ is the pre-requisite for course $i^{\prime \prime}$, thereby, efforts are also made to place $i$ on " $i$ ".

In accordance with Formula 8, the number of courses rendered is minimized in the final time-period (K) of the last midday $(\mathrm{R})$.

$$
\min \sum_{i=1}^{I} \sum_{j=1}^{J} \sum_{v=1}^{V} \sum_{m=1}^{M} \sum_{p=1}^{P} C_{i j r k v m p} \quad \begin{aligned}
& \forall r=R \\
& k=K
\end{aligned}
$$

In the eight abovementioned formulae, the objectives of the mathematical model for university course timetabling were presented. The hard constraints of programming are mentioned below.

The first set of constraints show that all the required groups of one course must be allocated. This constraint is presented in Formula 9.

$$
\sum_{j=1}^{J} \sum_{r=1}^{R} \sum_{k=1}^{K} \sum_{v=1}^{V} \sum_{m=1}^{M} \sum_{p=1}^{P} B_{i v} * C_{i j r k v m p}=L_{i}
$$

According to Formulae10 and 11, the maximum and minimum number of courses that each lecturer is permitted to tutor every week should be adhered. In other words, each lecturer can instruct the maximum of $\mathrm{Ma}_{\mathrm{p}}$ and the minimum $\mathrm{Mi}_{\mathrm{p}}$ hours every week (term).

$$
\sum_{i=1}^{I} \sum_{j=1}^{J} \sum_{r=1}^{R} \sum_{k=1}^{K} \sum_{v=1}^{V} \sum_{m=1}^{M} C_{i j r k v m p} * C T_{p i} * a_{v} \leq M a_{p}
$$




$$
\sum_{i=1}^{I} \sum_{j=1}^{J} \sum_{r=1}^{R} \sum_{k=1}^{K} \sum_{v=1}^{V} \sum_{m=1}^{M} C_{i j r k v m p} * C T_{p i} * a_{v} \geq M i_{p}
$$

The subsequent set deals with a non-intervention of the lecturers' program. According to Formula 12, each lecturer is only assigned to one course at each time -period in every division or dissection (midday).

$$
\sum_{i=1}^{I} \sum_{v=1}^{V} \sum_{m=1}^{M} C_{i j r k v m p} * C T_{p i} \leq 1 \quad \forall j, r, k, p
$$

In accordance with Formula 13, only one $v$-unit or $v^{\prime}$-unit of the courses should be allocated to each class every day (midday).

$$
\begin{aligned}
& \sum_{i=1}^{I} \sum_{k=1}^{K} \sum_{p=1}^{P}\left(C_{i j r k v m p}+C_{i j r k v^{\prime} m p}\right) \leq 1 \\
& \forall r, j, v, v^{\prime}, m \\
& v \neq v^{\prime}
\end{aligned}
$$

Based on Formulae 14 and 15, in each (midday) division only $v$-unit courses are assigned to $v$-unit timeperiods $\left(M K_{r v}\right)$ per day and classroom.

$$
\begin{array}{lr}
\sum_{i=1}^{I} \sum_{k=1}^{K} \sum_{p=1}^{P} C_{i j r k v m p} \leq M K_{r v} & \forall m, j, r, v \\
C_{i j r k v m p}=0 & \forall i, j, r, m, p \\
& v \geq 2 ; k>2
\end{array}
$$

Formula 15 indicates this point that in classes for more than two units, less than two courses are not allocated for each day or dissection.

On the basis of Formula 16, the number of students assigned to each class should not be more than the classroom capacity. In other words, depending on their capacity, the tutorials should be allocated to classrooms of equal or greater capacity.

$$
S_{i} * C_{i j r k v m p} \leq C_{m} \quad \forall i, j, r, k, v, m, p
$$

In Formula 17, an intrusion in respect to the curriculum and the classes is prevented, on the basis of which, each tutorial or lesson can be allotted to a class and an instructor (lecturer).

$$
\sum_{m=1}^{M} \sum_{p=1}^{P} \sum_{v=1}^{V} C_{i j r k v m p} \leq 1
$$

In the next constraint and within the mold of Formula 18 demonstrates that a lecturer should be in attendance at the university for counseling, in order to enhance educational quality, that is, one faculty member should attend at any time -period and in each (midday) division.

$$
\sum_{i=1}^{I} \sum_{v=1}^{V} \sum_{m=1}^{M} \sum_{p=1}^{n} M T_{p j r k v} *\left(1-C_{i j r k v m p} * C T_{p i}\right) \geq 1 \quad \forall j, r, k
$$


Formula 19 illustrates the constraint that, every day $j$, midday $r$, for time -period $k$ and for $v$-unit courses, the courses should only be allotted to lecturers who are present at the university. In other words, the courses are assigned to lecturers only when they are at the university.

$$
\sum_{i=1}^{I} \sum_{m=1}^{M} C_{i j r k v m p} \leq M T_{p j r k v} \quad \forall j, r, k, v, p
$$

Formula 20 determines the number of units of each course. Based on which, tutorial $i$ in day $j$, midday $r$, and time-period $k$ is presented in class $m$ by lecturer $p$, if the course or tutorial $i$ is in the $v$-unit form. It means that the presentation of each course, with that of its contradictory unit, is prevented in this constraint.

$$
C_{i j r k v m p} \leq B_{i v} \quad \forall i, j, r, k, v, m, p
$$

In the following constraint and Formula 21, the maximum hours for teaching for every lecturer per day is debated and it claims that, in the maximum, $z$-unit courses shall be presented for each lecturer $p$ per day $j$.

$$
\sum_{i=1}^{I} \sum_{r=1}^{R} \sum_{k=1}^{K} \sum_{v=1}^{V} \sum_{m=1}^{M} a_{v} * C_{i j r k v m p} \leq Z \quad \forall p, j
$$

In Formula 22 it is stated that, the courses or tutorials should only be assigned to lecturers who have the capabilities of teaching them.

$$
C_{i j r k v m p} \leq C T_{p i} \quad \forall i, j, r, k, v, m, p(22)
$$

By being attentive to the high number of objectives and constraints, which are considered in the problem, a numerical example was used to confirm the validity of the model. For solving the model, in a large dimension, a multi-objective non-dominated sorting genetic algorithm was presented.

\section{Non-dominated sorting genetic algorithm for university course timetabling}

As was mentioned in the earlier sections, the university course timetabling problem is converted into an NP-Hard problem if the dimensions are incremented by increasing the number of lecturers, lessons, classes, etc. Thus, it cannot be solved accurately. Non-deterministic algorithms like meta-heuristic and heuristic algorithms can be used to solve this problem. Eventually, a multi-objective and non-dominated sorting genetic algorithm is proposed for university course timetabling.

\subsection{Displaying the solution}

The manner of illustrating the response in a multi-objective non-dominated sorting genetic algorithm is by conforming to the variable $C_{i j r k v m p}$ in the mathematical model. In this model, the solution in respect to the programming of time-periods is considered as one hour and these one-hour time-periods are allocated to each course, according to the number of units rendered. On the basis of the number of units, each solution has as many chromosomes. Moreover, each chromosome includes a number of genes and each gene displays one of the subscripts of the variable $C_{i j r k v m p}$. Every solution is briefly shown in Figure 1: 


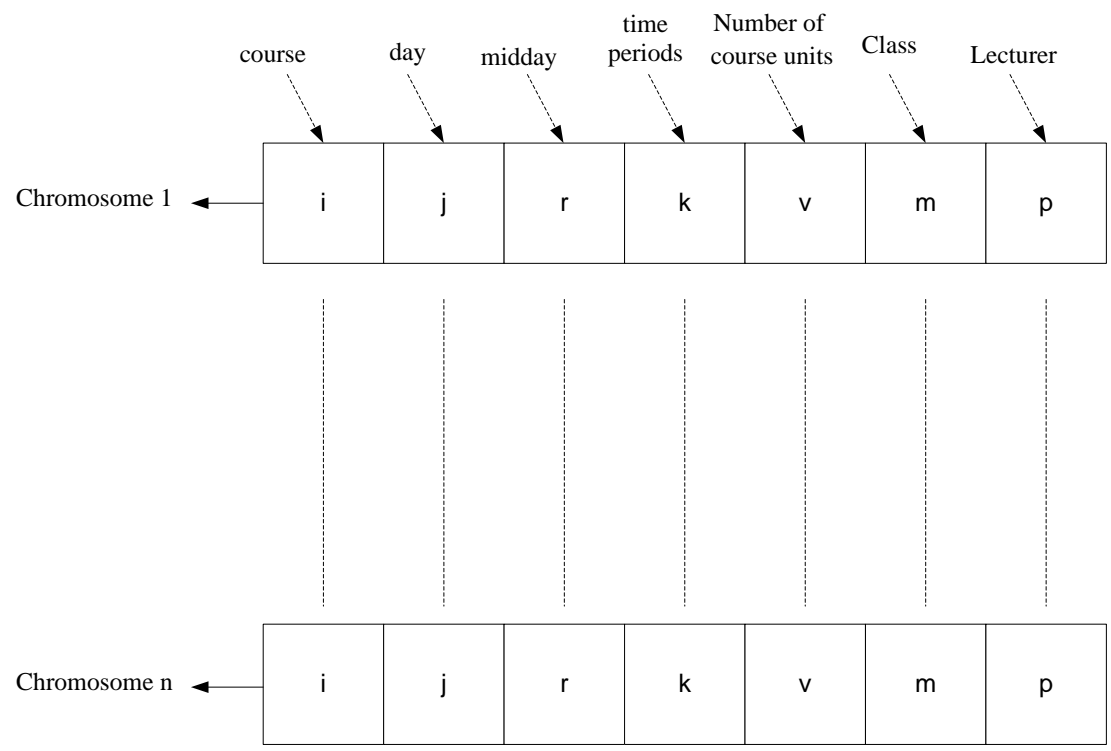

Figure 1. Displaying the solution of NSGA II

In the above figure, each row is a chromosome and the number of rows of matrix (number of chromosomes) is equal to the sum of the units required for programming (n).

\subsection{Production of primary population}

The primary population should be shaped in such a mode, so that the members of population can be selected at random from all the acceptable points of the mathematical model. Given the manner of illustrating the solution in the previous stage, there are a high number of dependent chromosomes related to each elucidation and modifying any chromosome can make the solution unacceptable. Thus, a three-stage algorithm is used to produce the primary population in order to prevent unwanted dispersions in the conventional range of the mathematical model. In this algorithm, at first, the courses that are presented by a lecturer only are identified. They are inserted in the weekly program by random selection for a day and a class, for the times, when the lecturer is present at the university. Having allocated all the courses that only one lecturer can teach the courses were assigned to all the lecturers in the second stage of the algorithm. For each lecturer, a minimum number of units (courses) are allotted in relevance to that specified course. At the end of this stage, the minimum number of courses is assigned to all the lecturers. The third stage continues with the purpose of forming the required groups for each course. Finally, at this stage, a weekly schedule is prepared. It is obvious that other constraints of the mathematical model are considered when all three stages are implemented.

\subsection{Selection operator}

In this section initially, the rate of response is computed on the basis of the (8) target functions defined in the mathematical model. It should be mentioned that, all the target functions are minimized for proper comparison. Then, the solutions are sorted according to the Pareto frontier based on a non-dominated sorting algorithm and the responses in each frontier are arranged internally according to the density of distance within the Pareto frontier. By using a roulette wheel, a frontier is selected at random and one member is determined as the parent which is probably proportional to the distance of density. It is obvious that in the first stage, frontiers with lower digits have a better chance of being selected; and the members 
with a higher distance of density in each frontier, have a higher chance of being designated. Subsequently, the second parent is selected in a similar manner. The two parents are used to create new members.

\subsection{Crossover Efficiency}

In this section, propagation is carried out by selecting two responses with the help of the crossover efficiency, resulting in outcomes. Thus, given that, in each response, for a number of units, of each course, chromosomes are present; and a high dependency exists amongst these chromosomes, in order to draw the response closer to being performed from the midday intersection. The first half of the day, from the first parent is combined with the second half-day from the second parent and creates the first issue. Whereas, the second half-day from the first parent mingles with the first half-day of the second parent and forms the second issue.

In continuation, the constraints of the problem are surveyed for the created issues. In the case that, the constraints have not been observed, the surplus courses are omitted and the ones remaining are re-allotted. In this step, the mutation performance also takes place with a determined probability and a section of the responses endures mutation. Members of the primary population, the new population and mutants are ranked iteratively and from amongst them, a new population, which is equivalent to the primary population, is selected for generation. This continues until it comes to a halting condition.

\section{Evaluating the results for solving the university course timetabling problem}

In order to explore the quality of solving the university course timetabling problem, some indexes are used which are defined along with soft constraints in the model and the results are examined through them. The indexes are determined as below:

\section{$\checkmark$ Ratio of days for the attendance of lecturers}

Due to the fact that, lecturers are recognized as one of the most crucial sources of educational programming, suitable programming for them can enhance their efficacy. Compactness in their program and a lack of intervals of futility between their classes can have an exceptional effect on their efficiency. In other words, if it could be feasible to reduce the number of days of their presence (at the faculty) to whatever extent, their costs, such as, for transportation and time, which could be wasted, would also be decreased.

Now, with due attention to the abovementioned issues, the number of days of the lecturers' attendance is surveyed using this index. The ratio of the number of days programmed, for the presence of each lecturer, in respect to the total number of days is considered in the planning.

$$
N D_{t}=\sum_{p} \frac{\text { programmed days for lecturer } p}{\text { total programmed days }}
$$

In noting the abovementioned definition, the lower the value of index $N D_{t}$, the better the programming.

\section{$\checkmark$ Quality level of lecturers in programming}

As it was pointed out, an increased quality in course timetabling is one of the most important purposes of educational programming. Any program that presents a higher quality level can realize a better purpose in this matter. Thus, the excellence of lecturers in the presented program is evaluated in this index and ratio of quality, in relevance to the program of a lecturer for each course, the highest quality for a lecturer is considered. 


$$
Q_{t}=\sum_{i} \frac{\text { quality of the programmed lecturer for course } i}{\text { the highest quality lecturer for the course }}
$$

In observing the abovementioned definition, the higher the value of index $Q_{t}$, the better the programming.

\section{$\checkmark$ Ratio of simultaneous courses}

As it was stated in the first index, i.e. ratio of days of lecturers' attendance in relative to total days of programming, compactness in the tutorial routine, can decrease transportation costs and time will not go waste. Given that the students cannot take some courses simultaneously, a synchronous presentation of courses will not disturb the tutorial routine of students and it can also assist in compressing schedule. In this index, a simultaneous presentation of some courses is explored. Eventually, the ratio of the number of groups presented simultaneously for the prerequisite and post academic courses is a necessity for all the required groups.

$$
S_{t}=\sum_{i} \frac{\text { the number of groups of simultaneous courses of course } i}{\text { total groups of simultaneous courses of course } i}
$$

Given the above definition, the higher the value of index $S_{t}$, the better the programming.

\section{$\checkmark$ Ratio of lessons rendered in the final time-period}

Given that efficiency of students and lecturers is lower at the final time -periods of the day and holding classes at these hours (of the day) usually lowers the effectiveness of the courses rendered at the final time -period of each day is studied in this index. Thus, the ratio of presented courses at the final period of each day in relative to the total courses is considered.

$$
\mathrm{R}=\frac{\text { number of courses in the final time interval }}{\text { total courses }}
$$

Given the abovementioned definition, the higher the value of the index R, the better the programming.

\section{Course timetabling for the Department of Industries at the Islamic Azad University, (Najaf Abad Branch)}

Since the university course timetabling problem is in big dimensions of NP-Hard and it cannot be solved accurately, this stage deals with course timetabling for the Department of Industries at the Islamic Azad University, (Najaf Abad Branch), by means of a non-dominated sorting genetic algorithm.

The required parameters determined for the timetable is according to Table 4 .

Then, the number of groups of each course, the number of units and capacity of students for each course is determined. Likewise, combined information of courses and lecturers, including lecturers who are able to teach each course and their excellence is determined in the intended course. This is shown in Table 5.

Then, the specifications of each lecturer, including their attendance program at the university and the maximum and minimum permissible hours for teaching, as well as the faculty (scientific) board members is determined. This is illustrated in Table 6. 
Finally, in order to gather data for the classes, the capacity of each class is determined. This is displayed in Table 7.

Given that the abovementioned information was determined for programming the graduate studies of Department of Industries at the Islamic Azad University, (Najaf Abad Branch), the course planning is carried out by a multi-objective, non-dominated sorting genetic algorithm. The parameters of the algorithm are determined in a way, so that the crossover parameter is performed on the basis of a dissection in the day, (i.e. morning till midday or noon and afternoon till the evening) for each program. Similarly, the mutation performance is considered stable and is equivalent to 0.4 . The number of population is equal to 1,000 and the generation integer has been contemplated and is equal to 50. In continuation, the encrypted code of the model is performed by the MATLAB Software.

Solving the model by using a multi-objective non-dominated sorting genetic algorithm maintains dominant solutions in each step and the responses are prioritized based on the distance of density within each population. At the termination and after completing the algorithm process, the obtained solutions are ranked and the suitable response is selected. For choosing a solution, usually the one with a higher rank is selected, but given that, there may be several solutions of similar rank, it must be decided on.

In taking under consideration that, the parameters, using a multi-objective, non-dominated sorting genetic algorithm will create 5,000 ranked solutions whose distance of intensity has been determined. The obtained solutions in this problem are equal to 15 with a ranking of 1 and the values of their distance of intensity are equal. Ultimately, one of the solutions should be selected; hence, multiple-criteria decision- making methods will be employed.

For selecting the final solution of the university course timetabling at the Department of Industries by the multiple-criteria decision making method, four indexes of the previous stage are used. In this respect, the VIKOR method is employed. First, the decision matrix is determined, which is according to Table 8:

The ratio of the days of the lecturers' attendance and the ratio of the courses rendered at the final timeperiods are considered as two negative indexes in the abovementioned decision matrix. In other words, the lower their value, the better. Then, the weight of each index is calculated by means of the Shannon Entropy Method. The final solution of the university course timetabling in the Department of Industries at the Islamic Azad University, (Najaf Abad Branch), was selected by the VIKOR Method. Solution number 5 was selected as the final solution and the results of programming were extracted to draw-up the university course timetable. This is shown in Table 9. 


\section{Conclusion}

An improvement of educational quality has created many challenges for universities. Though, appropriate programming of university courses can be highly effective. Universities are permanently faced with course timetabling. In this programming, educational resources such as lecturer, class, tutorial, etc. are assigned to a series of time-periods. As university course timetabling, has been a challenging aspect for universities since the past, several researchers have proposed strategies to resolve it in recent years.

In view of the importance of university course timetabling, a mathematical model was proposed in this study and then, a meta-heuristic, multi-objective, non-dominated sorting genetic algorithm was rendered for solving it. The most important innovation of the proposed model is that, it considers the programming quality of tutorial presentation. The dimensions of quality comprise of the following cases:

1- The excellence of lecturers in each lesson

2- Attendance of at least one lecturer at the university for counseling

3- Simultaneous presentation of some courses

4- Terminating classes at the final time-period of a day.

The university course timetabling problem on an actual scale is converted into an NP-Hard problem as its dimensions are immense. Thus, a multi-objective, non-dominated sorting genetic algorithm was proposed for the programming of graduate studies at the Department of Industries. To determine the dominant and recessive solutions, the Pareto frontier technique was used in this algorithm.

In the current research, the proposed model was solved by the NSGA II algorithm with different parameters. Moreover, the university course timetable for graduate studies in industrial engineering was obtained using several parameters. Then, timetables with different parameters were explored by means of assessment indexes and the final timetable was selected.

The results disclosed that the employed algorithm has a suitable efficiency in determining the university course timetabling. One of the main advantages of this model is that it can be used by the personnel for educational planning at the universities. They can use the proposed model for university course timetabling. Given that, a high number of constraints in the real world have been resolved, it is hoped that the universities will have access to an appropriate timetable which is acceptable for lecturers and students using this model and algorithm. Attendance of a faculty member at any period of time for counseling has been extremely beneficial for the proposed model.

One of the major constraints of this problem was its large dimensions in the programming of genuine cases, so that an accurate solving of the said, in dimensions of the real problem was impossible. Due to this reason, it was difficult to compare the solution by precise methods and the NSGA II algorithm.

Besides considering the normal soft and hard constraints in preparing the university course timetabling in this study, educational quality was considered as one of the most important educational concerns of managers of institutions. It is for this reason that, there are some constraints, in the proposed mathematical model. Moreover, with due attention to the fact that, there are secluded constraints in each university, besides the constraints which are revealed and prove to be applicable only to that particular university, the obtained results, may not affirm the total desirability. Hence, researchers can add other constraints to the 
model or they can present heuristic algorithms in future studies in which the intended constraints are considered.

In the same manner, future researchers can consider limitations such as pre-requisite relations and the difference between the core and optional courses and solve the problem by utilizing innovative algorithms, other than the heuristic NSGA II algorithm.

\section{References}

$\checkmark$ Abdelhalim, E.A. and El Khayat, G.A. (2016). “A Utilization-based Genetic Algorithm for Solving the University Timetabling Problem (UGA)". Alexandria Engineering Journal, Vol. 55, No. 2, pp. 13951409.

Abdullah, S. (2006). Heuristic approaches for university timetabling problems, thesis for the degree of Doctor of Philosophy, The School of Computer Science and Information Technology, university of Nottingham.

$\checkmark$ Abdullah, S. and Alzaqebah, M. (2013). "A hybrid self-adaptive bees algorithm for examination timetabling problems". Applied Soft Computing, Vol. 13, No. 8, pp. 3608-3620.

$\checkmark$ Agustín-Blas, L.E., Salcedo-Sanz, S., Ortiz-García, E.G., Portilla-Figueras, A. and Pérez-Bellido, A.M.(2009). "A hybrid grouping genetic algorithm for assigning students to preferred laboratory groups". Expert Systems with Applications, Vol. 36, No. 3, pp. 7234-7241.

$\checkmark$ Al-Yakoob, S.M. and Sherali, H.D. (2006). "Mathematical programming models and algorithms for a class-faculty assignment problem". European Journal of Operational Research. Vol. 173, No. 2, pp. 488-507.

$\checkmark$ Al-Yakoob, S.M. and Sherali, H.D. (2015). "Mathematical Models and Algorithms for a High school timetabling problem". Computers \& Operations Research. Vol. 61, No. 1, pp. 56-68.

$\checkmark \quad$ Alvarez-Valdes, R., Crespo, E. and Tamarit, J.M. (2002). "Design and implementation of a course scheduling system using Tabu Search". European Journal of Operational Research, Vol. 137, No. 3, pp. 512-523.

$\checkmark \quad$ Badoni, R.P., Gupta, D.K. and Mishra, P. (2014). "A new hybrid algorithm for university course timetabling problem using events based on groupings of students". Computers \& Industrial Engineering. Vol. 78, No. 1, pp. 12-25.

$\checkmark$ Basir, N., Ismail, W. and Norwawi, N.M. (2013). "A Simulated Annealing for Tahmidi Course Timetabling". Procedia Technology, Vol. 11, No. 1, pp. 437-445.

$\checkmark$ Beligiannis, G.N., Moschopoulos, C.N., Kaperonis, G.P. and Likothanassis, S.D. (2008). "Applying evolutionary computation to the school timetabling problem: The Greek case". Computers \& Operations Research, Vol. 35, No. 4, pp. 1265-1280.

$\checkmark \quad$ Bellio, R., Ceschia, S., Gaspero, L.D., Schaerf, A. and Urli, T. (2016). "Feature-based tuning of simulated annealing applied to the curriculum-based course timetabling problem". Computers \& Operations Research. Vol. 65, No. 1, pp. 83-92.

$\checkmark$ Bolaji, A.L., Khader, A.T., Al-Betar, M.A. and Awadallah, M.A. (2014). "University Course Timetabling using Hybridized Artificial Bee Colony with Hill Climbing Optimizer", Journal of Computational Science, Vol. 5, No. 5, pp. 809-818.

$\checkmark$ Borchani, R., Elloumi, A. and Masmoudi, M. (2017). "Variable neighborhood descent search based algorithms for course timetabling problem: Application to a Tunisian University". Electronic Notes in Discrete Mathematics. Vol. 58, No. 1, pp. 119-126.

$\checkmark$ Burke, E. K., Marecek, J., Parkes, A.J. and Rudová, H. (2010). "Decomposition, reformulation, and diving in university course timetabling". Computers \& Operations Research, Vol. 37, No. 3, pp. 582597. 
$\checkmark$ Cacchiani, V., Caprara, A., Roberti, R. and Toth, P. (2013). "A new lower bound for curriculumbased course timetabling”. Computers \& Operations Research. Vol. 40, No. 10, pp. 2466-2477.

$\checkmark$ Carter, M.W., and Laporte, G. (1998). Recent developments in practical course timetabling. In E.K. Burke, and P. Ross (Eds.), Selected papers from the $2^{\text {nd }}$ international conference on the practice and theory of automated timetabling (pp. 3-19). Lecture Notes in Computer Science, Springer.

$\checkmark$ Causmaecker, P.D., Demeester, P. and Berghe, G.V. (2009). "A decomposed metaheuristic approach for a real-world university timetabling problem". European Journal of Operational Research. Vol. 195, No. 1, pp. 307-318.

$\checkmark$ Ceschia, S., Gaspero, L.D. and Schaerf, A. (2012). "Design, engineering, and experimental analysis of a simulated annealing approach to the post-enrolment course timetabling problem". Computers \& Operations Research, Vol. 39, No. 7, pp. 1615-1624.

$\checkmark$ Domenech, B. and Lusa, A. (2015). "A MILP model for the teacher assignment problem considering teachers' preferences". European Journal of Operational Research. Vol. 249, No. 3, pp. 11531160.

Fong, C.W., Asmuni, H.b., McCollum, B., McMullan, P. and Omatu, S. (2014). "A new hybrid imperialist swarm-based optimization algorithm for university timetabling problems". Information Sciences. Vol. 283, No. 1, pp. 1-21.

$\checkmark$ Goh, S.L., Kendall, G. and Sabar, N.R. (2017). "Improved local search approaches to solve the post enrolment course timetabling problem". European Journal of Operational Research. Vol. 261, No. 1, pp. $17-29$.

$\checkmark$ Gunawan, A., Ng, K.M. and Poh, K.L. (2012). "A hybridized Lagrangian relaxation and simulated annealing method for the course timetabling problem". Computers \& Operations Research. Vol. 39, No. 12, pp. 3074-3088.

$\checkmark$ Hao, J.K. and Benlic, U. (2011)"Lower bounds for the ITC-2007 curriculum-based course timetabling problem". European Journal of Operational Research, Vol. 212, No. 3, pp. 464-472.

$\checkmark$ Head, C. and Shaban, S. (2007). "A heuristic approach to simultaneous course/student timetabling". Computers \& Operations Research, Vol. 34, No. 4, pp. 919-933.

$\checkmark \quad$ Lewis, R. Thompson, J. (2015). "Analysing the effects of solution space connectivity with an effective metaheuristic for the course timetabling problem". European Journal of Operational Research, Vol. 240, No. 3, pp. 637-648.

$\checkmark \quad$ Lü, Z. and Hao, J.K. (2010). “Adaptive Tabu Search for course timetabling”. European Journal of Operational Research. Vol. 200, No. 1, pp. 235-244.

$\checkmark$ Mahiba, A.A., Durai, A.D. (2012). "Genetic Algorithm with Search Bank Strategies for University Course Timetabling Problem". Procedia Engineering, Vol. 38, No. 1, pp. 253-263.

$\checkmark$ Méndez-Díaz, I., Zabala, P. and Miranda-Bront, J.J. (2016). "An ILP based heuristic for a generalization of the post-enrollment course timetabling problem". Computers and Operation Research. Vol. 76, No. 1, pp. 195-207.

$\checkmark$ MirHassani, S.A. (2006). "A computational approach to enhancing course timetabling with integer programming”. Applied Mathematics and Computation, Vol. 175, No. 1, pp. 814-822.

$\checkmark$ Naji Azimi, Z. (2005). "Hybrid heuristics for Examination Timetabling problem". Applied Mathematics and Computation, Vol. 163, No. 2, pp. 705-733.

$\checkmark$ Phillips, A., Waterer, H., Ehrgott, M. and Ryan, D. (2014). "Integer Programming Methods for Large Scale Practical Classroom Assignment Problems”. Computers \& Operations Research. Vol. 53, No. 1, pp. 42-53.

$\checkmark$ Pongcharoen, P., Promtet, W., Yenradee, P. and Hicks, C. (2008). "Stochastic Optimisation Timetabling Tool for university course scheduling". International Journal of Production Economics, Vol. 112, No. 2, pp. 903-918. 
$\checkmark$ Qaurooni, D. and Akbarzadeh-T, M.R. (2013). "Course timetabling using evolutionary operators". Applied Soft Computing, Vol. 13, No. 5, pp. 2504-2514.

$\checkmark$ Sabar, N.R., Ayob, M., Kendall, G. and Qu, R. (2012). "A honey-bee mating optimization algorithm for educational timetabling problems". European Journal of Operational Research. Vol. 216, No. 3, pp. 533-543.

$\checkmark$ Santiago-Mozos, R., Salcedo-Sanz, S., DePrado-Cumplido, M. and Bousoño-Calzón, C. (2005). "A two-phase heuristic evolutionary algorithm for personalizing course timetables: a case study in a Spanish university". Computers \& Operations Research, Vol. 32, No. 7, pp. 1761-1776.

$\checkmark$ Shiau, D.F. (2011). "A hybrid particle swarm optimization for a university course scheduling problem with flexible preferences". Expert Systems with Applications. Vol. 38, No. 1, pp. 235-248.

$\checkmark$ Smith, K.A., Abramson, D. and Duke, D. (2003). "Hopfield neural networks for timetabling: formulations, methods, and comparative results". Computers \& Industrial Engineering, Vol. 44, No. 2, pp. 283-305.

$\checkmark$ Soria-Alcaraz, J.A., Ochoa, G., Swan, J., Carpio, M., Puga, H. and Burke, E.K. (2014). "Effective learning hyper-heuristics for the course timetabling problem". European Journal of Operational Research. Vol. 238, No. 1, pp. 77-86.

$\checkmark \quad$ Soria-Alcaraz, J.A., Özcan, E., Swan, J., Kendall, G. and Carpio, M. (2016). "Iterated local search using an add and delete hyper-heuristic for university course timetabling". Applied Soft Computing. Vol. 40, No. 1, pp. 581-593.

$\checkmark \quad$ Soza, C., Becerra, R.L., Riff, M.C. and Coello, C.A.C. (2011). "Solving timetabling problems using a cultural algorithm". Applied Soft Computing. Vol. 11, No. 1, pp. 337-344.

$\checkmark$ Studenovský, J. (2009). "Polynomial reduction of time_space scheduling to time scheduling". Discrete Applied Mathematics. Vol. 157, No. 7, pp. 1364-1378.

$\checkmark$ Tounsi, M. and Ouis, S. (2008). "An Iterative local-search framework for solving constraint satisfaction problem". Applied Soft Computing, Vol. 8, No. 4, pp. 1530-1535.

$\checkmark$ Vermuyten, H., Lemmens, S., Marques, I. and Belien, J. (2016). "Developing compact course timetables with optimized student flows". European Journal of Operational Research. Vol. 251, No. 2, pp. $651-661$.

$\checkmark \quad$ Wu, C.C. (2011), "Parallelizing a CLIPS-based course timetabling expert system". Expert Systems with Applications, Vol. 38, No. 6, pp. 7517-7525.

$\checkmark$ Zhang, D., Liu, Y., M'Hallah, R. and Leung, S.C.H. (2010). "A simulated annealing with a new neighborhood structure based algorithm for high school timetabling problems". European Journal of Operational Research, Vol. 203, No. 3, pp. 550-558. 
